\title{
Wind Tunnel Test for Vortex-induced Vibration of Vehicle-bridge System Section Model
}

State Key Laboratory for Disaster Reduction in

Civil Engineering

China Railway Shanghai Design Institute Group Corporation Limited

China

Yaojun Ge

yaojunge@mail.tongji.edu.cn State Key Laboratory for Disaster Reduction in Civil Engineering China
Vortex-induced vibration of bridges happens at a relatively low wind speed and while vehicles often run on a bridge at that wind speed. Thus, it is necessary to study how the vehicles influence vortex-induced vibration of vehicle-bridge systems. Based on the project of Shanghai Bridge over Yangtse River, the wind tunnel test for vortex-induced vibrations of vehicle-bridge system of a 1:60 model is presented. The wind tunnel test is introduced in detail including the equipments, test procedures and discussion of results. The results show that the vehicles have much influence on vortex-induced vibration of vehicle-bridge system for the Shanghai Bridge over Yangtse River. With speed increasing, the displacement of the bridge with vehicles fluctuates larger than that of the bridge without vehicles. The frequencies of vibration could be divided into three stages, vertical vibration frequency for the first stage, torsional vibration frequency for the second stage, and suspension system vibration frequency for the third stage. For the bridge with vehicles, vertical vortexinduced vibration was accompanied with torsional vibration and the frequencies of the two vibrations are equal. The displacement of vortex-induced vibration for the bridge with vehicles was larger than that of vortex-induced vibration for the bridge without vehicles. Due to the disturbance of vehicles, the lock-in wind speed region of the vortex-induced vibration appears ahead.

Keywords: Shanghai Bridge over Yangtse River, vehicle-bridge system, vortex-induced vibration, wind tunnel test

\section{Introduction}

The vortex-induced vibrations of closed-box girder bridge decks have attracted attention of researchers in recent years. For the long span bridge, vortex-induced vibration of beam is due to the fact that when air flow rounds the bridge section, vortex develops in the two sides of the section. And these lead to the pressure changing alternately, and the section develops the crosswind direction force. Frequency of the crosswind direction force is "locked" and vortexinduced vibration happens at lock-in wind speed. As a lively example of real bridge, during the final phases of deck erection and surfacing of the suspended spans of the Storebalt Bridge, vertical deck oscillations of low frequency were observed by workers and supervision staff (Larsen etc. 2000).

In the case of long-span bridges, Ehsan and Scanlan (1990), employing basic data from deck section wind tunnel model tests, offered a nonlinear theoretical framework for predicting maximum vortex-induced amplitude under the lock-in condition. By converting some of the Ehsan-Scanlan experimental section data to the new form, Scanlan (1998) successfully identified the range of original Tacoma Narrows vortex-induced response amplitudes that were experimentally obtained by Farquharson on a full-bridge model. Either vertical or torsionalal motions at vortex lock-in can be assayed by the method discussed. Diana et al. (2004) presented a new original experimental rig to more deeply investigate the aerodynamic behaviour of long span suspension bridges including the vortex shedding. Larose et al.(2004) made a 1:20 scale model to study the vortex-induced vibration phenomenon at high Reynolds number. Hosomi (1997) proposed a numerical stochastic method to calculate the number of cycles of vortex-induced oscillation considering that aerodynamic responses appear in a wide range of wind direction.

Wind can not only lead to passengers discomfort but also causes bridge to be damaged and deteriorated. Aerodynamic performance of bridges is very sensitive to sectional shape and detailed structure of the section. Wind acts on vehicles as well as on bridges, and

Paper accepted November, 2007. Technical Editor: Domingos Alves Rade. vehicles on a bridge can change the airflow someway. The wind tunnel test of vehicle-bridge system is mainly focused on the trainbridge system today. The test and study in this field is being engaged in by Li (2001, 2004), Huang (2001), Xia (2000), Cai (2004), Xu (2003) who have undertaken a great deal of research work in the field of vehicle-bridge-wind system. However they all use the quasi-static model to calculate the force of vehicle and wind is considered to act on vehicles and bridge separately. Reinhold (1993) dealt with influence of vehicle on vortex-induced vibration response in the test of the Great Belt East Suspension Bridge.

Vortex-induced vibration of beams usually happens at low wind speed and if vortex-induced vibration happens frequently and sustains longer, which will cause fatigue damage to the bridge, pedestrian and vehicle users discomfort (Xiang and Ge, 2002). Vortex-induced vibration is the emphasis of the bridge wind resistance because the vortex shape has much relation with the shape of bridge section. It is very important to study vortex-induced vibration of vehicle-bridge system by means of the wind tunnel test as the theory of vortex-induced vibration is not perfect and numerical simulation methods have some limitations today. In this context, based on the project of Shanghai Bridge over Yangtse River, this paper presents a 1:60 scale sectional model study at TJ-1 wind tunnel and a summary of the main findings on vortex-induced vibration of vehicle-bridge system.

\section{Nomenclature}

$$
\begin{aligned}
& L_{s} \quad=\text { length of section model } \\
& W_{s} \quad=\text { width of section model } \\
& H_{s}=\text { height of section model } \\
& M_{e} \quad=\text { equivalent mass of section model } \\
& J_{m} \quad=\text { mass inertia of section model } \\
& F_{h}=\text { vertical frequency of section model } \\
& F_{t}=\text { torsional frequency of section model } \\
& U \quad=\text { wind speed of wind tunnel } \\
& \xi_{h}=\text { vertical damp ratio of section model } \\
& \xi_{t} \quad=\text { torsion damp ratio of section model } \\
& L_{v} \quad=\text { length of vehicle model } \\
& W_{v}=\text { width of vehicle model } \\
& H_{v} \quad=\text { height of vehicle model }
\end{aligned}
$$


Tests

\section{Engineering Background}

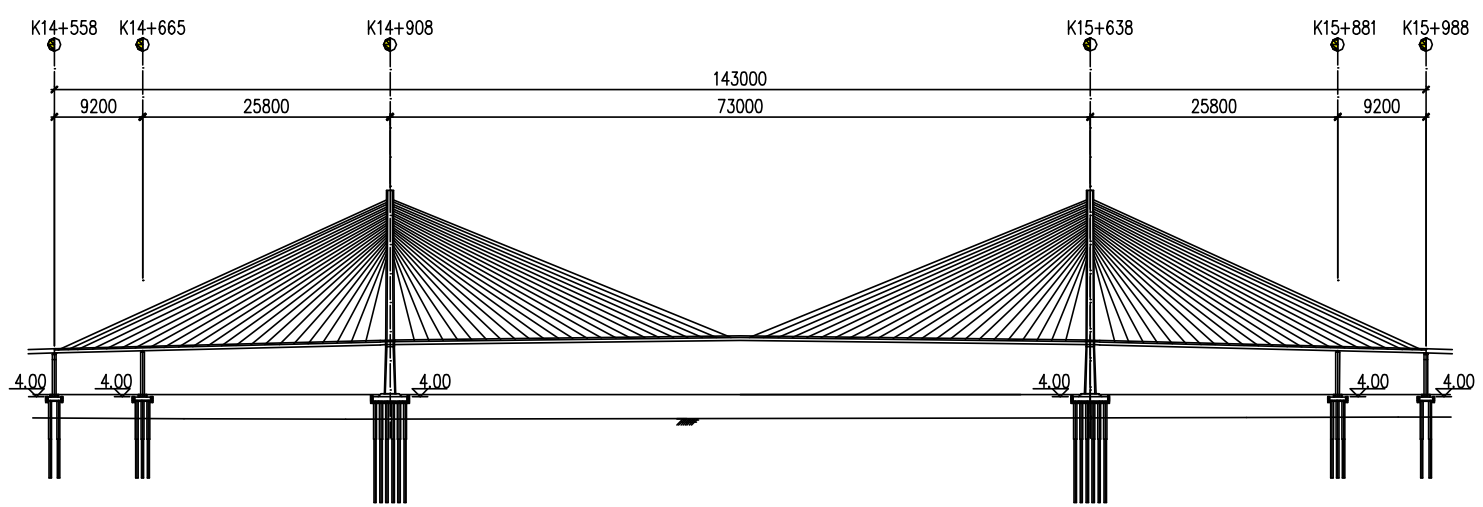

Figure 1. The elevation of shanghai bridge over Yangtse River

\section{The Design of Model}

A combination of geometrical, mass and stiffness resulted in the selection of a 1:20 geometrical scale for the sectional model of the Shanghai Bridge over Yangtse River (Tab. 1). The dynamic sectional model scaling links the velocity scaling with the frequency scaling. The main dimension of section model refers to Fig. 2. The shape of the mode must be similar to that of the beam, and the rigidity of the model must be as large as possible. The weight of the model should not exceed the design weight due to the scale of the strain-gauge balance. The frame of the model was made of aluminum alloy and the surface was made of veneer lumber. The main structural stiffness of the model was provided by a spar, one in each box, consisting of an aluminum H-beam. The model had a simply-supported natural frequency in bending of $25 \mathrm{~Hz}$.

Table 1. The main parameter of section model.

\begin{tabular}{c|c|c|c|c}
\hline Parameter & Unit & Real value & $\begin{array}{c}\text { Similarity } \\
\text { ratio }\end{array}$ & $\begin{array}{c}\text { Model } \\
\text { value }\end{array}$ \\
\hline$L_{s}$ & $\mathrm{~m}$ & 102 & $1: 60$ & 1.700 \\
\hline$W_{s}$ & $\mathrm{~m}$ & 51.5 & $1: 60$ & 0.858 \\
\hline$H_{s}$ & $\mathrm{~m}$ & 4 & $1: 60$ & 0.067 \\
\hline$M_{e}$ & $\mathrm{~kg} / \mathrm{m}$ & 35151 & $1: 60^{2}$ & 9.771 \\
\hline$J_{m}$ & $\mathrm{~kg}-\mathrm{m}^{2} / \mathrm{m}$ & 10076000 & $1: 60^{4}$ & 0.778 \\
\hline$F_{h}$ & $\mathrm{~Hz}$ & 0.252 & $17: 1$ & 4.284 \\
\hline$F_{t}$ & $\mathrm{~Hz}$ & 0.665 & $14: 1$ & 9.310 \\
\hline$\xi_{h}$ & $\%$ & 0.5 & $1: 1$ & 0.5 \\
\hline$\xi_{t}$ & $\%$ & 0.5 & $1: 1$ & 0.5 \\
\hline
\end{tabular}

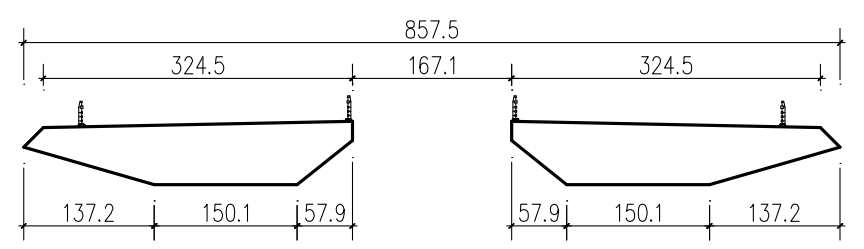

(a) Section drawing

Figure 2. Section model drawing of beam.
Shanghai Bridge over Yangtse River has an overall length of $1430 \mathrm{~m}$ with $730 \mathrm{~m}$ main span and two side spans including two holes of $92 \mathrm{~m}$ and $258 \mathrm{~m}$ each (see Fig.1). The tower reaches a height of $216.32 \mathrm{~m}$. The twin-box deck girder is $51.5 \mathrm{~m}$ wide and 4 $\mathrm{m}$ deep, composed of two steel boxes, 20.75 wide.

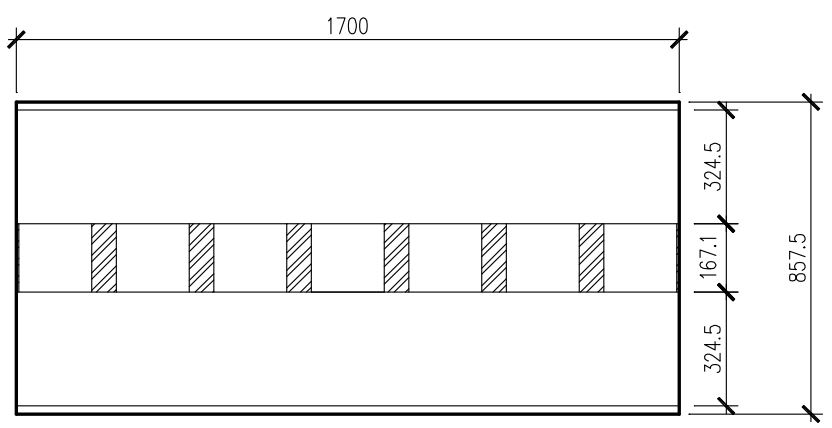

(b) Plane drawing

Figure 2. (Continued).

\section{Vehicle Layout}

When the vehicle is moving, the leading and following vehicles should remain at safe-distance in the same roadway. When speed is $100 \mathrm{~km} / \mathrm{h}$, distance between neighboring vehicles should not be less than $100 \mathrm{~m}$. When speed is $70 \mathrm{~km} / \mathrm{h}$, distance should not be less than $70 \mathrm{~m}$. In the test, the length of the section model is $1.7 \mathrm{~m}$ corresponding to $102 \mathrm{~m}$ of the actual distance. It seems rational to place one vehicle on each roadway. Six kinds of typical vehicles were selected in the tests. The dimension of the vehicles model refers to Tab. 2. The layout chart of vehicle is shown in Fig. 3.

Table 2. The dimension of vehicle model ( $\mathrm{mm})$.

\begin{tabular}{c|c|c|c|c|c|c}
\hline & $\begin{array}{c}\text { Yellow } \\
\text { roadster }\end{array}$ & $\begin{array}{c}\text { Blue } \\
\text { car }\end{array}$ & $\begin{array}{c}\text { Yellow } \\
\text { van }\end{array}$ & $\begin{array}{c}\text { Middle } \\
\text { bus }\end{array}$ & Bus & $\begin{array}{c}\text { Container } \\
\text { Car }\end{array}$ \\
\hline$L_{v}$ & 65 & 65 & 73 & 80 & 101 & 118 \\
\hline$W_{v}$ & 30 & 28 & 28 & 32 & 28 & 28 \\
\hline$H_{v}$ & 20 & 24 & 33 & 32 & 39 & 44 \\
\hline
\end{tabular}




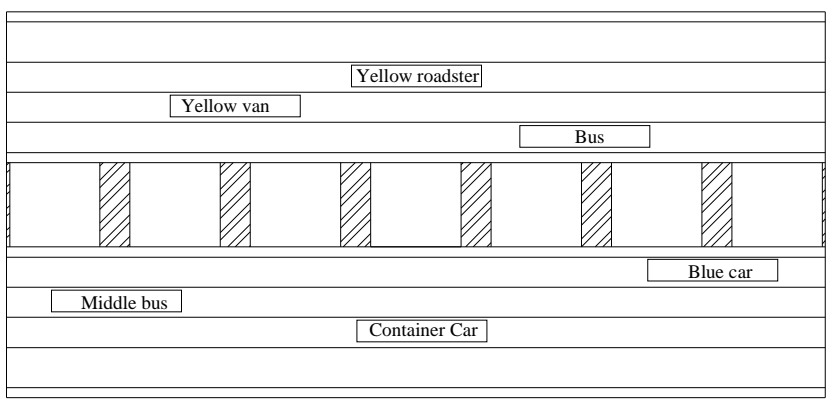

Figure 3. The layout chart of vehicle.

\section{Equipment}

The wind tunnel tests for vortex-induced vibration of 1:60 beam model was done at TJ-1 wind tunnel of State Key Laboratory for Disaster Reduction in Civil Engineering (see Fig. 6) based on the project of the Shanghai Bridge over Yangtse River. The test included six conditions of bridge without vehicle and bridge with vehicle for angles of attack of $-3^{\circ}, 0^{\circ}$ and $+3^{\circ}$. The equipments used in the test were following:

\section{Boundary layer wind tunnel}

All tests were performed in smooth flow in TJ-1's $1.8 \mathrm{~m} \times 1.8 \mathrm{~m}$, $12 \mathrm{~m}$ long wind tunnel which can achieve speeds from $1 \mathrm{~m} / \mathrm{s}$ to $30 \mathrm{~m} / \mathrm{s}$. It is a wind tunnel designed with a suitable contraction ratio to ensure low turbulence intensity and flow uniformity in the test section. The longitudinal turbulence intensity in the centre of the test near the sectional model position was measured lower than $1 \%$. This is enough to assure that the wind speed was even at the height of model and the upstream speed profile need not to be measured. In the test Pitot tubes were used to measure wind speed near the model, and it lied in front of the model and a little higher than the height of the model.

\section{Suspension system}

Eight springs were disposed in sectional model, four at each extremity of the model, all of them working in parallel. They were connected to a restraining arm linking the model to the suspension system. Figure 4 and Figure 5 are the lateral view and top view of model junction device, respectively. The ends of all springs were suspended on the vertical rotating mechanisms. The suspension system lied out of the wind tunnel.

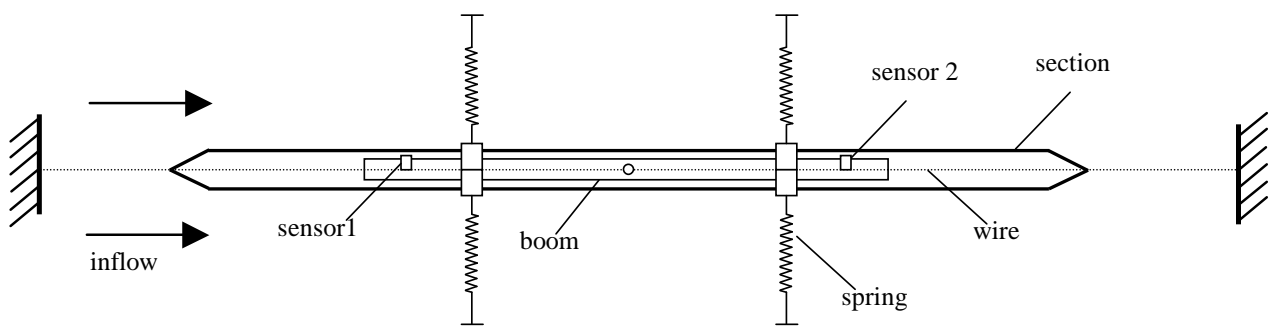

Figure 4. Lateral view of model junction device.

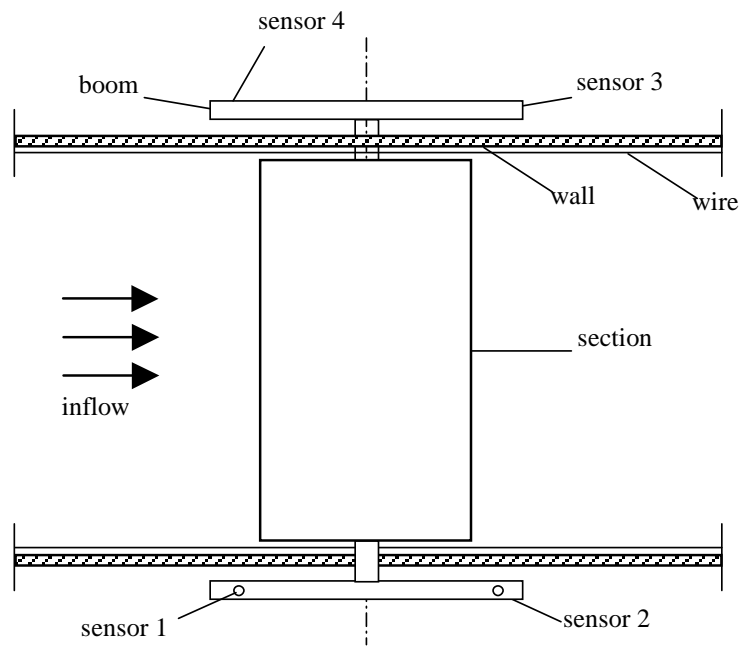

Figure 5. Top view of model junction device.

3. Piezoelectric accelerometer sensor: $C A-Y D-103$.

Four sensors were fixed on the arms symmetrically away from the centre of rotation of the model.

4. NI sampling panels and computer data acquisition system.

5. Six channels vibration amplifier YE5866.

6.Four channels dynamic signal analysis meter HP35670A. It was used to monitor the vibration frequency.
The later three equipments and computers are located in the control room.

\section{Test Procedure}

After equipments are installed, the test followed the following procedures. 
1. Before the test, parameters of acquisition cards were set: sampling frequency was $200 \mathrm{~Hz}$ and sampling time was 40 s.

2. In each condition, there were two times of wind tunnel test. For the first time, its aim was to find the probable lock-in wind speed.

3. Before the lock-in, sampling wind speed interval was $0.2 \mathrm{~m} / \mathrm{s}$, and sampling wind speed interval was $0.1 \mathrm{~m} / \mathrm{s}$ near and in the lockin. It was necessary to wait wind speed to become stable before sampling.

4. After sampling, acceleration signal was exchanged to the displacement signal and statistic analysis using Matlab® program.

5. For each angle of attack, the vortex induced-vibration test was done for the bridge with vehicles and without vehicles, successively.

6. At the end of the test in this attack angle, it was very convenient to rotate the model to exchange attack angle by vertical rotating mechanisms, as can be seen in Fig 6 .

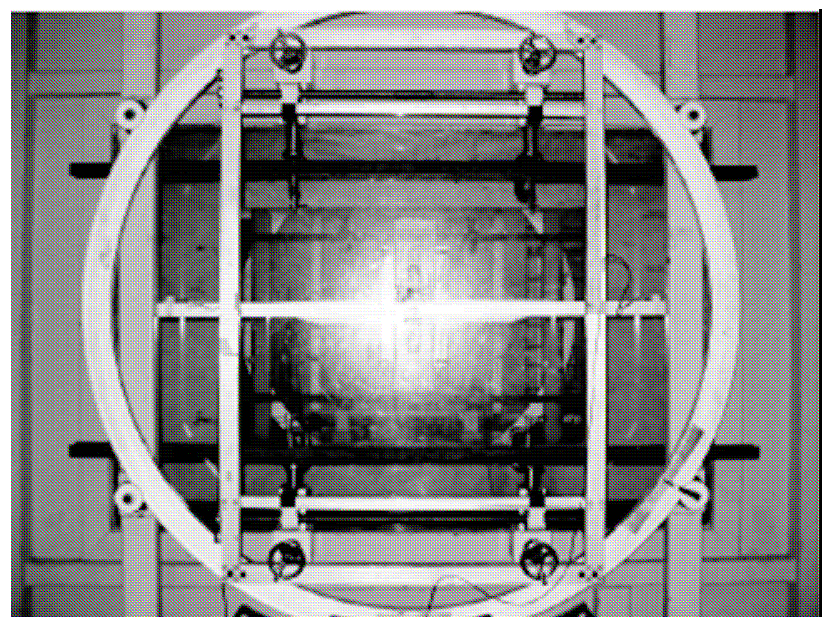

(a) Spring suspension system

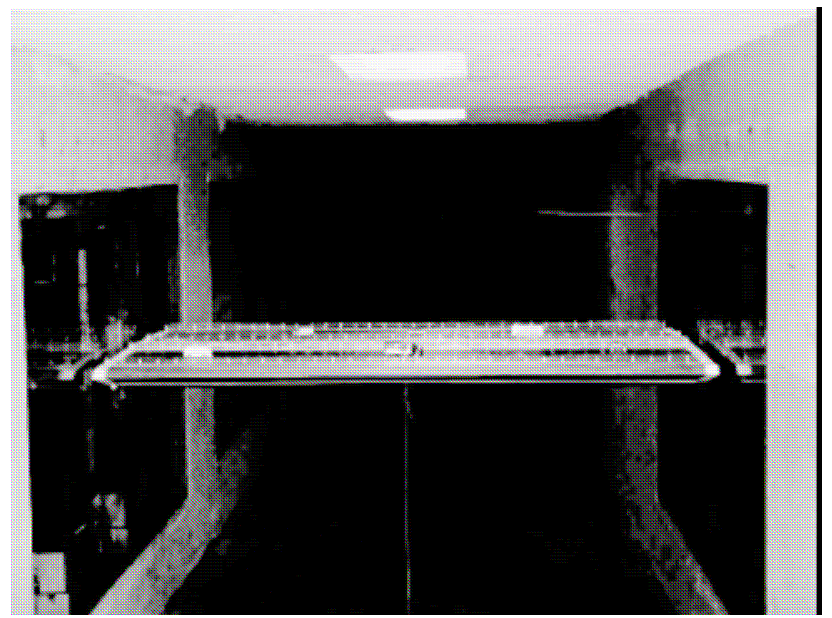

(b) Section model with vehicle

Figure 6. Section model of the wind tunnel test.

\section{Test Uncertainties}

There are many uncertainties that can affect the results of the tests. In all uncertainties, turbulence intensity and damping ratios are two important aspects. When they are larger, they could inhibit vortex-induced vibration and vice versa. The scale of the model is also one of the important aspects; a bigger scale should be used for the further study.

\section{Results and Discussion}

Vortex-induced vibration for vertical and torsional motion of the models was observed for the bridge without vehicle and the bridge with vehicle.

\section{Comparison of Displacement oor $0^{\circ}$ Attack Angle}

As an example of searching the lock-in, Figure 7 shows the time histories when model scale wind speed is increased from $4.4 \mathrm{~m} / \mathrm{s}$ to $5.4 \mathrm{~m} / \mathrm{s}$ at $0^{\circ}$ attack angle. The amplitude of time histories was low at the speed of $4.4 \mathrm{~m} / \mathrm{s}$ and the amplitude increased to a lager value when the speed increased by only $0.1 \mathrm{~m} / \mathrm{s}$. The amplitudes of vibration between $4.4 \mathrm{~m} / \mathrm{s}$ to $5.3 \mathrm{~m} / \mathrm{s}$ are approximate, and we see this region as vortex-induced lock-in region. However, the amplitude becomes lesser again at $5.4 \mathrm{~m} / \mathrm{s}$.

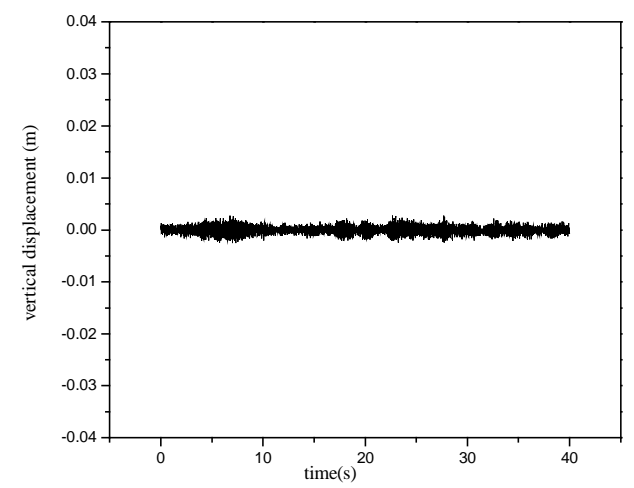

(a) $4.4 \mathrm{~m} / \mathrm{s}$ vertical displacement

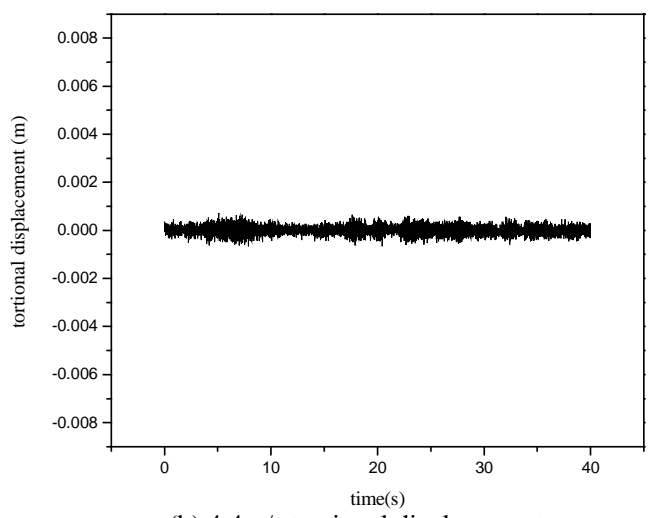

(b) $4.4 \mathrm{~m} / \mathrm{s}$ torsional displacement

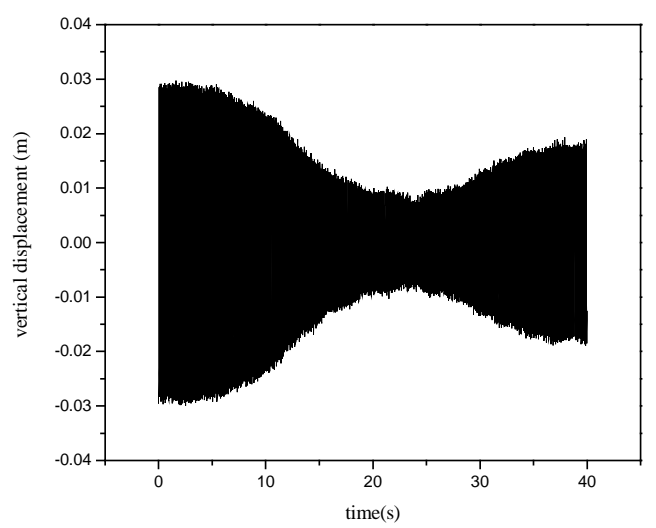

(c) $4.5 \mathrm{~m} / \mathrm{s}$ vertical displacement

Figure 7. Time histoties from $4.4 \mathrm{~m} / \mathrm{s}$ to $5.4 \mathrm{~m} / \mathrm{s}$ for wind tunnel speed. 


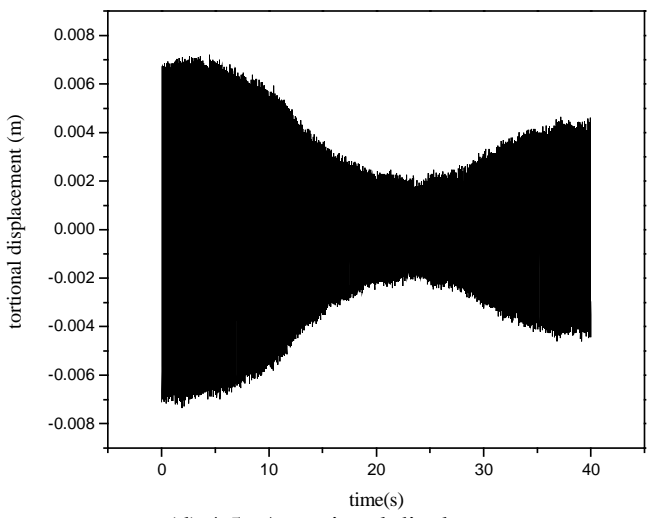

(d) $4.5 \mathrm{~m} / \mathrm{s}$ torsional displacement

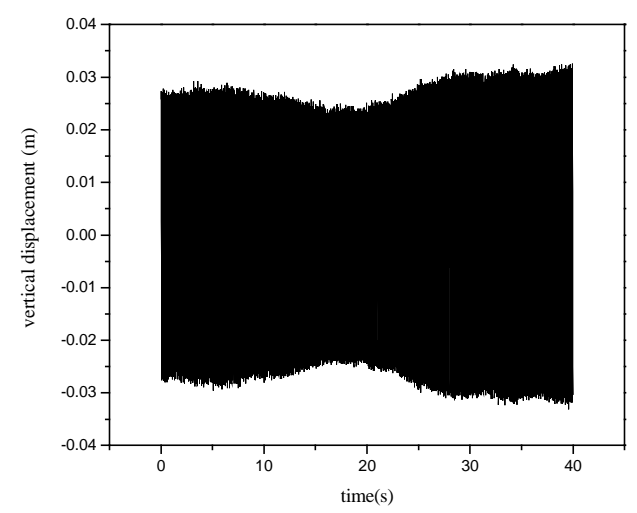

(e) $4.7 \mathrm{~m} / \mathrm{s}$ vertical displacement

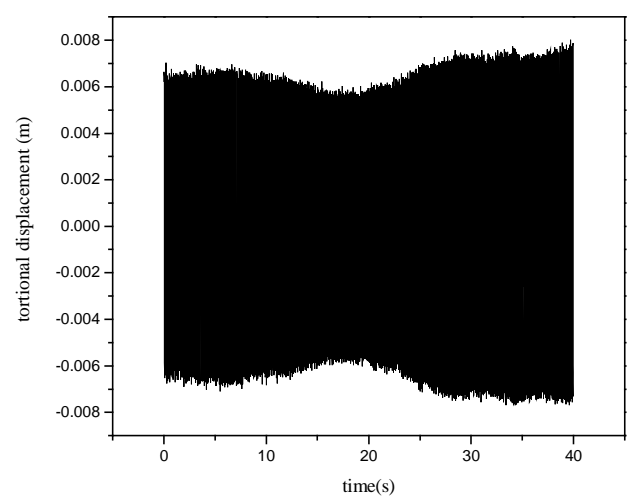

(f) $4.7 \mathrm{~m} / \mathrm{s}$ torsional displacement

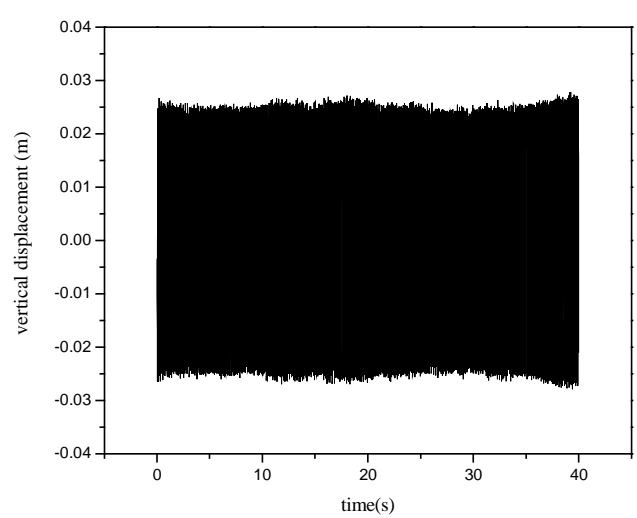

(g) $4.9 \mathrm{~m} / \mathrm{s}$ vertical displacement

Figure 7. (Continued).

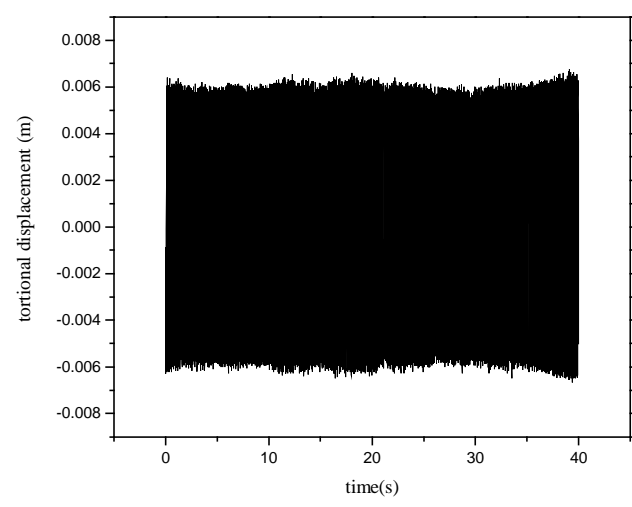

(h) $4.9 \mathrm{~m} / \mathrm{s}$ torsional displacement

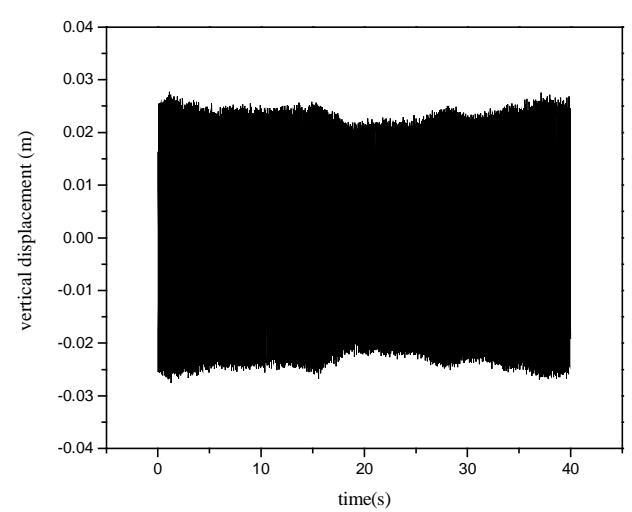

(i) $5.3 \mathrm{~m} / \mathrm{s}$ vertical displacement

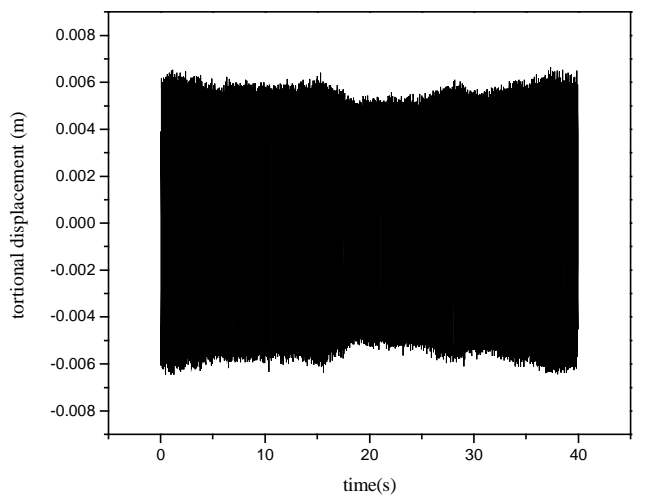

(j) $5.3 \mathrm{~m} / \mathrm{s}$ torsional displacement

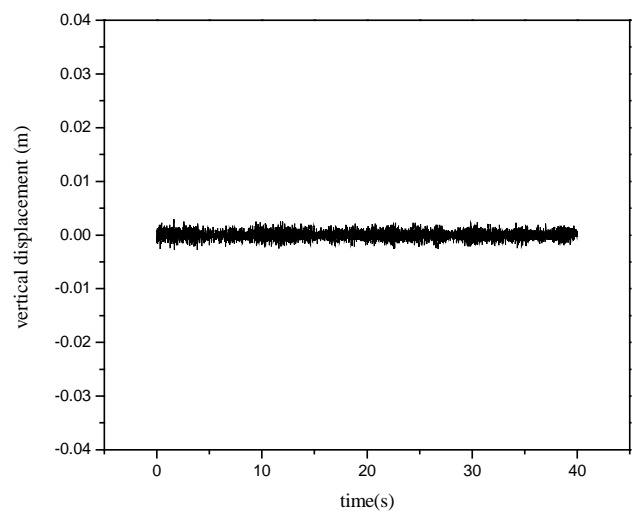

(k) $5.4 \mathrm{~m} / \mathrm{s}$ vertical displacement

Figure 7. (Continued). 


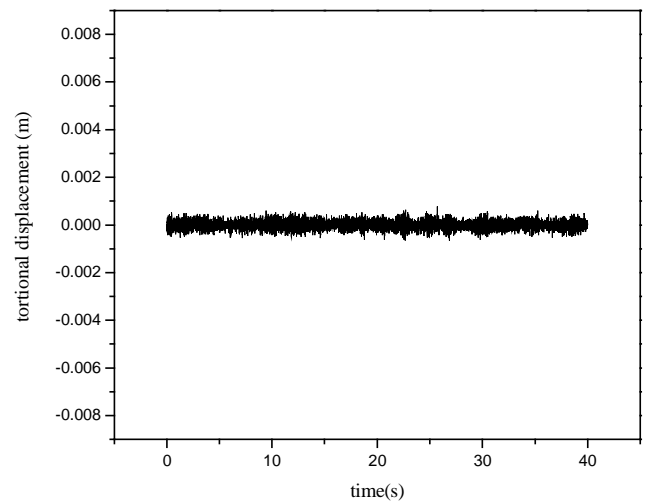

(1) $5.4 \mathrm{~m} / \mathrm{s}$ torsional displacement

Figure 7. (Continued).

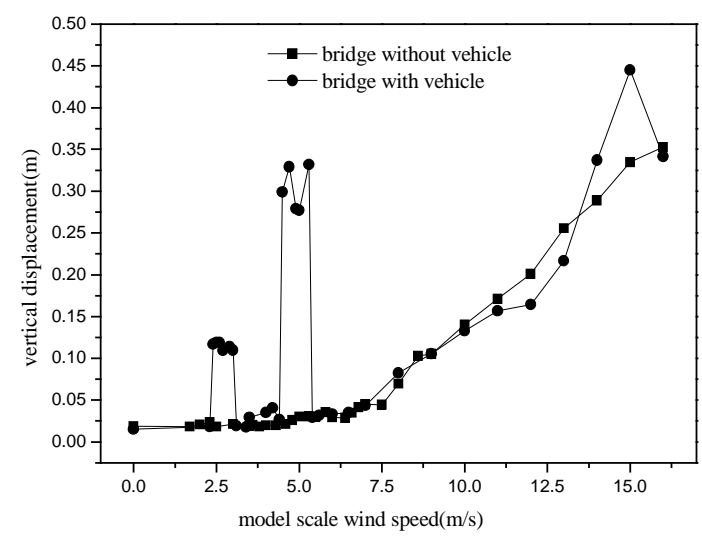

Figure 8. Curve of $0^{\circ}$ vertical displacement - speed.

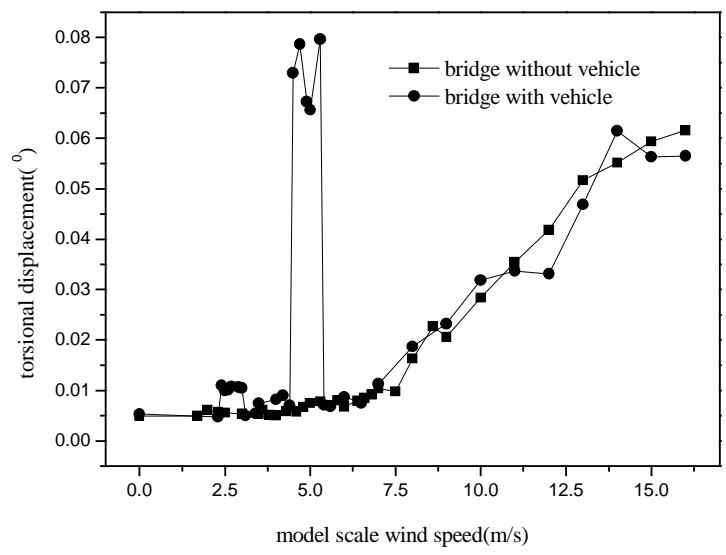

Figure 9. Curve of $0^{\circ}$ torsional displacement peak value- speed.

Figure 8 and figure 9 show curves of displacement-model scale wind speed at the $0^{\circ}$ attack angle, and two vortex-induced vibration peaks were observed in each figure. We found that displacement of the bridge with vehicles fluctuated larger than that of the bridge without vehicles. Figure 10 presents curves of vibration frequencymodel scale wind tunnel speed for vertical signal and torsional signal. With wind tunnel speed increasing, the frequencies of vibration experienced three stages, vertical vibration frequency for the first stage, torsional vibration frequency for the second stage, and suspension system vibration frequency for the third stage.

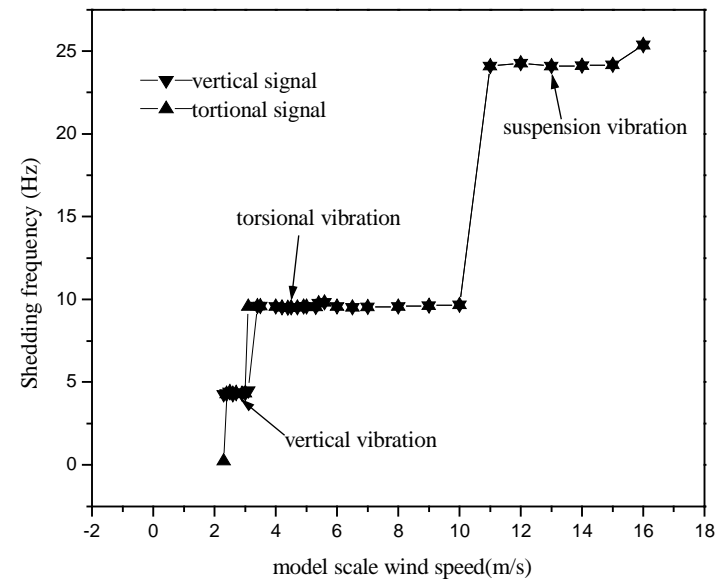

Figure 10. The curve of Frequency- wind tunnel speed.

As can be seen in Fig. 8, the bridge without vehicles has not obvious vortex-induced vibration, however the bridge with vehicle has vertical vortex-induced vibration with the amplitude of $0.117 \mathrm{~m}$ when the lock-in region was from $2.4 \mathrm{~m} / \mathrm{s}$ to $3.0 \mathrm{~m} / \mathrm{s}$. At the same time the vertical vortex-induced vibration (Fig. 8) was accompanied with torsional vibration (Fig. 9) due to the uneven vehicle layout, uneven pressure and the exquisite vortex-induced vibration. As can be seen from Fig. 9, the first peak value was the result of coincident torsional vibration (amplitude $0.011^{\circ}$ ). The frequency of vertical vortex-induced vibration (Fig. 8) was $4.297 \mathrm{~Hz}$ (see Fig. 11), just the first stage of Fig. 10.

As can be seen from Fig. 9, torsional vortex-induced vibration for the bridge with vehicles happens with the amplitude of $0.08^{\circ}$ when the lock-in wind speed was from $4.5 \mathrm{~m} / \mathrm{s}$ to $5.3 \mathrm{~m} / \mathrm{s}$ and accompanied with vertical vibration at the same time. As can be seen in Fig. 8, the second peak value was the coincident vertical vibration (amplitude $0.332 \mathrm{~m}$ ). Its frequency was equal to the torsional frequency of $9.570 \mathrm{~Hz}$ (Fig. 12), just the second stage of Fig. 10.

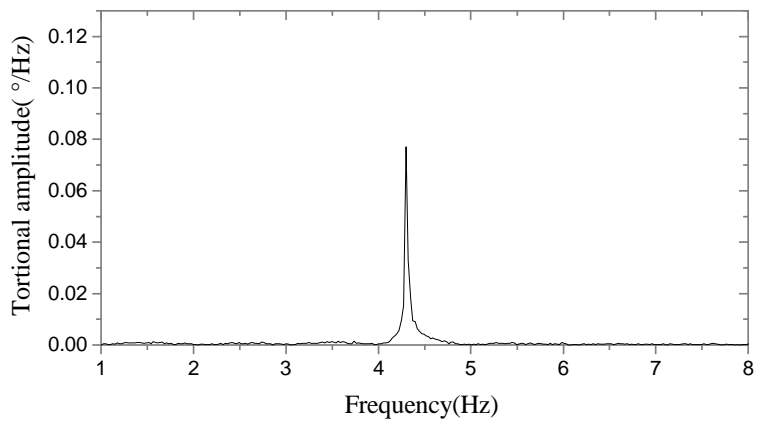

Figure11. 8. $4 \mathrm{~m} / \mathrm{s}$ vortex frequency.

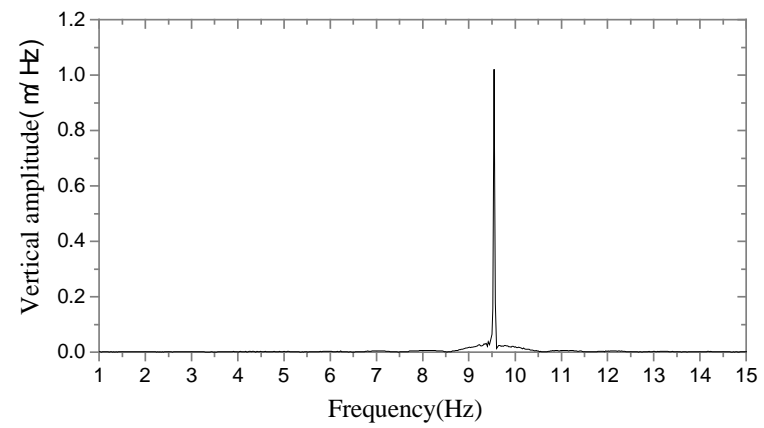

Figure 12. $21.9 \mathrm{~m} / \mathrm{s}$ vortex frequency. 


\section{Comparison of Displacements for $+3^{\circ}$ Attack Angle}

Figure 15 and Figure 16 show the curves of displacement-model scale wind speed at $+3^{\circ}$ attack angle, and the displacement of bridge with vehicles fluctuated larger than that of bridge without vehicles, just like for $0^{\circ}$ attack angle.

As can be seen from Fig. 13, the lock-in wind speed region of vertical vortex-induced vibration moves from $3.4 \mathrm{~m} / \mathrm{s} \square 3.65 \mathrm{~m} / \mathrm{s}$ for bridge without vehicles to $2.85 \mathrm{~m} / \mathrm{s} \square 3.1 \mathrm{~m} / \mathrm{s}$ for bridge with vehicles ahead, due to disturbance of the vehicles which made the lock-in wind speed ahead. As can be seen in Fig. 14, the two vertical vortex-induced vibrations were accompanied with two coincident torsional vibrations with less amplitude.

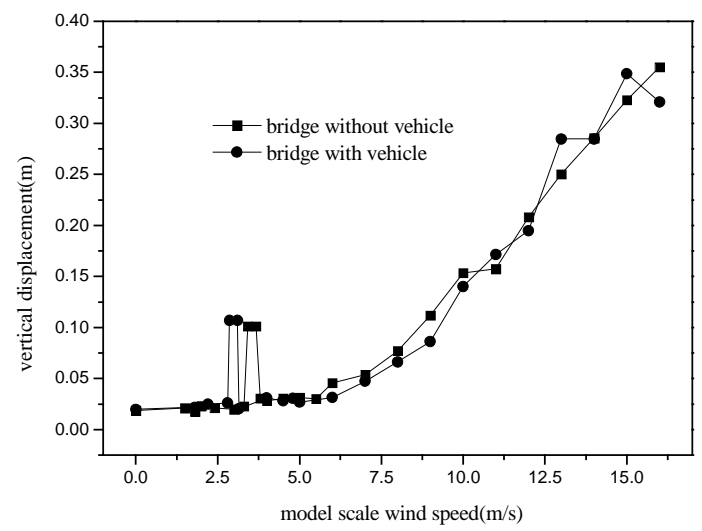

Figure 13. Curve of $+3^{\circ}$ vertical displacement - speed.

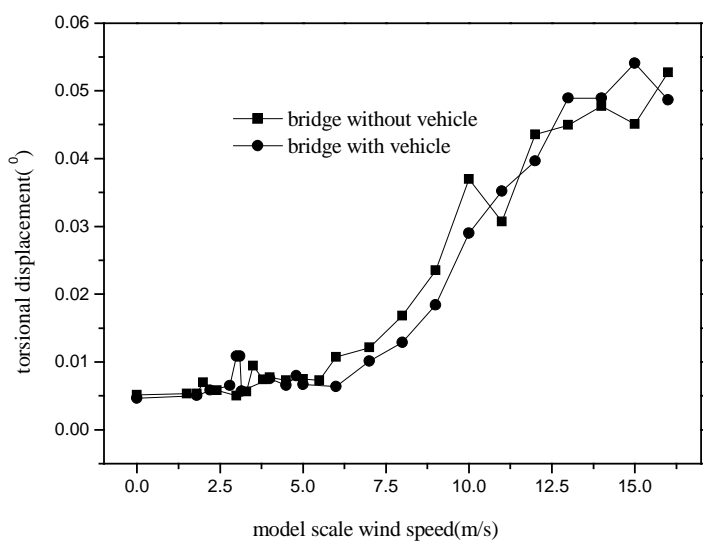

Figure 14. Curve of $+3^{\circ}$ torsional displacement peak value- speed.

\section{Comparison of Displacements for $-3^{\circ}$ Attack Angle}

As can be seen in Fig. 15, bridge without vehicles has not obvious vortex-induced vibration for $-3^{\circ}$ attack angle, whilst bridge with vehicle has obvious vortex-induced vibration with the amplitude of $0.122 \mathrm{~m}$ when the lock-in regions were $1.35 \mathrm{~m} / \mathrm{s} \sim 1.5 \mathrm{~m} / \mathrm{s}$ and $2.0 \mathrm{~m} / \mathrm{s} \sim 2.2 \mathrm{~m} / \mathrm{s}$. At the same time the section vertical vortexinduced vibration was accompanied with torsional vibration due to the uneven vehicle layout and uneven pressure (as can be seen in Fig. 16). Frequency of the accompanied vibration was $4.321 \mathrm{~Hz}$ which was equal to frequency of vertical vortex-induced vibration.

As can be seen in Fig. 16, torsional vortex-induced vibration for the bridge with vehicle happens with the amplitude of $0.019^{\circ}$ when the lock-in regions was from $4.52 \mathrm{~m} / \mathrm{s}$ to $6.0 \mathrm{~m} / \mathrm{s}$ and accompanied with vertical vibration at the same time. As can be seen in Fig. 15, the third peak value correspond to vertical vibration (amplitude
$0.084 \mathrm{~m})$. Its frequency was equal to the torsional frequency $9.619 \mathrm{~Hz}$.

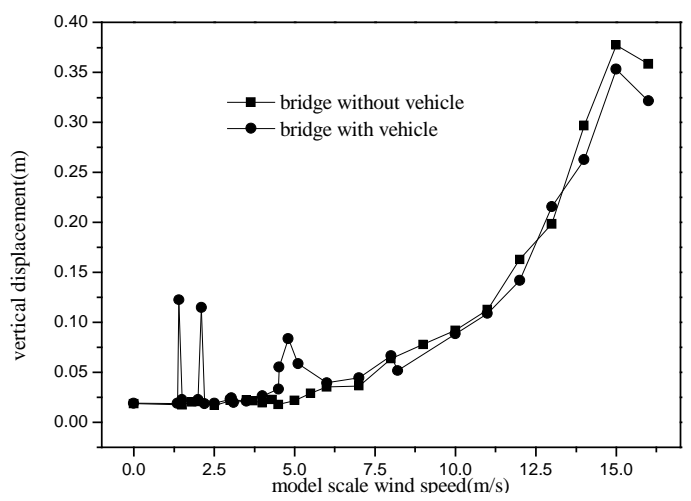

Figure 15. Curve of $-3^{\circ}$ vertical displacement - speed.

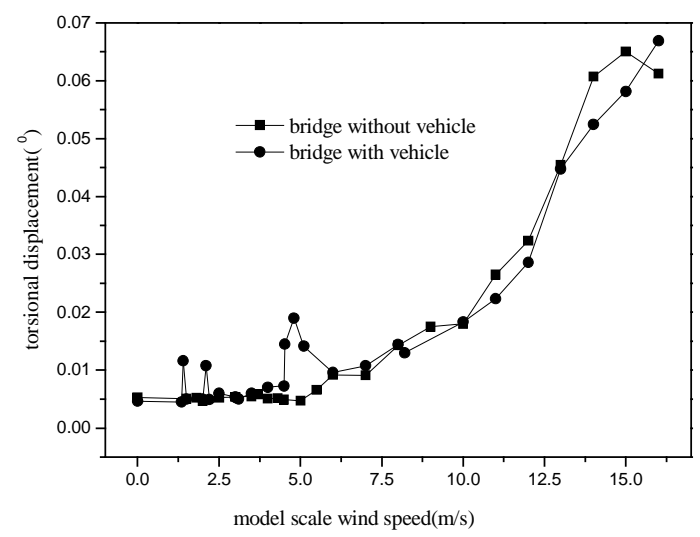

Figure 16. Curve of $-3^{\circ}$ torsional displacement peak value- speed.

\section{Conclusions}

Vortex-induced vibration of vehicle-bridge system section model for Shanghai Bridge over Yangtse River was studied in the TJ-1's $1.8 \mathrm{~m} \times 1.8 \mathrm{~m}$ Wind Tunnel. A 1:60 scale sectional model of the deck was built and mounted in a spring suspension system to investigate, in an aero-elastic context, vehicle's effect on the vortexinduced vibration of bridge deck. After the analysis and comparison, the following conclusions can be drawn:

With wind tunnel speed increasing, the displacement of bridge with vehicles fluctuated larger than that of bridge without vehicles and the frequencies of vibration experienced three stages, vertical vibration frequency for the first stage, torsional vibration frequency for the second stage, suspension system vibration frequency for the third stage. Due to disturbance of vehicle, the locked region of vortex-induced vibration lock-in wind speed appears ahead at attack angle $+3^{\circ}$.

For the bridge with vehicles, vertical vortex-induced vibration was accompanied with torsional vibration and the frequencies of them were equal.. The coincident torsional/vertical vibration happens due to the uneven vehicle layout and uneven pressure with the exquisite vertical/torsional vortex-induced vibration.

The amplitude of vortex-induced vibration for the bridge with vehicle was bigger than that of vortex-induced vibration for bridge without vehicle. Vortex-induced vibration for bridge without vehicle does not happen at $0^{\circ}$ attack angle. Torsional vortex-induced vibration for bridge with vehicles happens with the amplitude of 
$0.08^{\circ}$ and the amplitude of coincident vertical vibration reaches $0.332 \mathrm{~m}$.

\section{Acknowledgments}

The authors are grateful for the financial support from the National Natural Science Foundation projects (No.50538050).

\section{References}

Cai, C.S., Chen, S.R. 2004, "Framework of vehicle-bridge-wind dynamic analysis", Journal of Wind Engineering and Industrial Aerodynamics, Vol. 92, pp. 579-607.

Diana, G., Resta, F., Zasso , A., Belloli, M., Rocchi, D., 2004, "Forced motion and free motion aeroelastic tests on a new concept dynamometric section model of the Messina suspension bridge", Journal of Wind Engineering and Industrial Aerodynamics, vol. 92, pp. 441-462.

Ehsan F., Scanlan, R. H.,1990. "Vortex-induced vibration of flexible bridges." ASCE Journal of Engineering and Mechanical., vol. 116, pp. $1392-1411$.

Gammal , M. E., Hangan, H., King, P., 2007, "Control of vortex shedding-induced effects in a sectional bridge model by spanwise perturbation method", Journal of Wind Engineering and Industrial Aerodynamics, vol. 95, pp. 663-678.

Hosomi, M., Kobayashi H., Nitta,Y., 1997, “ Fatigue strength design for vortex-induced oscillation and buffeting of a bridge", Journal of Wind Engineering and Industrial Aerodynamics, vol. 67\&68, pp. 227-237.
Huang L., Liao H.L. 2001, "Analysis of flow characteristics around high-speed railway bridge-vehicle system under cross wind", Journal of southwest jiaotong university, vol. 40, pp. 585-590.

Larose, G.L., Larsen, S.V., Larsen, A., Jensen, A.G., Sectional model experiments at high Reynolds number for the deck of a $1018 \mathrm{~m}$ span cablestayed bridge.

Larsen, A., Esdahl S., Andersen J. E., Vejrum T., 2000, "Storebñlt suspension bridge \pm vortex shedding excitation and mitigation by guide vanes", Journal of Wind Engineering and Industrial Aerodynamics, vol. 88, pp. 283-296

Li Y.L., Liao H.L.. Qiang S.Z. 2004, "Study on aerodynamic characteristics of the vehicle bridge system by the section model wind tunnel test ", Journal of the china railway society, vol. 26, pp. 71 75.

Reinhold T, Larsen A, Damsgaard A , 1993, Svensson E. Wind tunnel testing for the great belt east suspension bridge, Proceedings of the Symposium on Structural Engineering in Natural Hazards Mitigation, pp. 496-501

Scanlan R.H., 1998, "Bridge flutter derivatives at vortex lock-in", Journal of Structural Engineering, Vol. 124, pp. 450-458.

Xia H., Xu Y. L., Chan T. H .T., 2000, "Dynamic interaction of long suspension bridges with running trains", Journal of Sound and Vibration, vol. 237, pp. 263-280.

Xiang, H.F., Ge, Y. J., 2002, "Refinements on aerodynamic stability analysis of super long-span bridges", Journal of Wind Engineering and Industrial Aerodynamics, vol. 90, pp. 1493-1515.

Xu, Y.L., Guo, W.H..2003, "Dynamic analysis of coupled road vehicle and cable-stayed bridge systems under turbulent wind", Engineering Structures, vol. 25, pp. 473-486. 